\title{
MULTISENSORY STRUCTURED LEARNING IN LIGHT OF AGE FACTOR: VOCABULARY DEVELOPMENT IN CROATIAN ENGLISH AS A FOREIGN LANGUAGE LEARNERS WITH DYSLEXIA
}

\author{
Agnieszka Kałdonek-Crnjakovićn \\ Institute of English Studies, University of Warsaw
}

This longitudinal case study (two years and seven months) that involved two learners with dyslexia of different ages aimed to investigate the benefit of the Multisensory Structured Learning (MSL) approach in vocabulary learning in English as a foreign language (EFL). The results showed that MSL is an approach that could improve vocabulary learning in a foreign language (FL) in learners with dyslexia of different ages. However, age is a salient factor. The results corroborate previous findings on the effect of MSL and add to the literature in the field with new findings on the impact of the age factor. The pedagogical implications of the study stress the importance of incorporating a structured, explicit, and multisensory approach into a regular classroom to help learners with dyslexia overcome their difficulties with FL learning.

Keywords: dyslexia, Multisensory Structured Learning, English as a foreign language, vocabulary development, age factor

\section{INTRODUCTION}

There is a common agreement that teaching foreign language (FL) skills to learners with dyslexia should be based on the Multisensory Structured Learning (MSL) approach (e.g. Kormos \& Smith, 2012; Nijakowska, 2010; Schneider \& Crombie, 2003; Schneider \& Ganschow, 2000), and there is some empirical evidence confirming its positive effect in teaching EFL literacy skills (e.g. Kałdonek-Crnjaković, 2015; Nijakowska, 2008; Pfenninger, 2015).

Since dyslexia is a complex phenomenon, vocabulary development in FL in learners with dyslexia using the MSL approach has been investigated in individuals or small groups. The studies examining vocabulary learning in English as a foreign language (EFL) by learners with dyslexia included a report of learning experience of an individual case (Sarkadi, 2008), a selfreporting account of difficulties in acquiring new vocabulary (Kormos \& Kontra, 2008; Kormos \& Mikó, 2010 in Kormos \& Smith, 2012), and vocabulary learning in English as a third language (Pfenninger, 2015). Since

a.kaldonek2@uw.edu.pl 
such research is scarce, this study seeks to extend the current understanding of vocabulary development in EFL in learners with dyslexia in the context of MSL instruction.

This study aimed at verifying whether MSL can be a beneficial approach in teaching EFL vocabulary to learners with dyslexia in light of the age factor. To measure the effect of the age factor, two EFL learners participated in the study; a primary school-age child and a young adult in his early twenties.

The progress the participants were making was monitored by measuring long-term retrieval and the need for overlearning of the phrases the participants were learning. The study focused on the development of productive vocabulary knowledge.

The novelty of the study lies in the fact that this was the first study that considered the age effect regarding the effect of the MSL approach. The period of investigation in this study was also more extended than in the previous ones, and none of the earlier studies involved learners with dyslexia with Croatian as the mother tongue.

\section{THEORETICAL BACKGROUND}

Vocabulary acquisition in an FL is a complex process that involves the recognition of auditive and visual forms of the word, the knowledge of its morphosyntactic and semantic properties and the integration of the word into the mental lexicon (Jiang, 2004; Oxford \& Scarcella, 1994).

Vocabulary learning happens intentionally, that is explicitly, or incidentally, when one, for example, is involved in listening or reading activities (Hulstijn, 1997). There is no agreement as to which way is more successful (Zimmerman, 2014). Schmitt (2008) endorses intentional learning because an individual can learn more when they pay more attention. Nation (2001), on the other hand, suggests the meaning of the word should be taught explicitly, whereas its form is best acquired incidentally.

Recent research findings suggest that teaching words in English as a second language in isolation may be more effective than teaching them in integrated activities (File \& Adams, 2010).

Also, to learn a new word, one needs an ample time of overlearning. Nation (1990) suggests that the learner needs to encounter a word between five and 16 times to learn it, whereas Webb (2007) found that ten learning occasions of a new word are not enough to learn all of its aspects.

Some recent studies have confirmed the frequency of encounters as a significant factor in vocabulary development in EFL. For example, Peters (2014) found that the vocabulary items that occurred five times were recalled three times more often than those that happened only once, for both single words and collocations. However, collocations were more challenging to learn and thus recall for them was lower. The researcher yet pointed out 
that it was difficult to give a precise number that a learner should encounter a phrase to successfully recall it because of the significant differences in the findings.

In a recent study, Bao (2015) found that contextual clues, frequent encounters of the word, and the learner's awareness of the target word are far more critical factors in developing vocabulary in EFL, both receptive and productive, than the learner's involvement in the vocabulary task.

However, age may be a salient factor in vocabulary development in FL. In younger learners, it is a long process as the child needs to be exposed to the word many times in different contexts to eventually learn it (Cameron, 2001; Vilke, 1991). From the teaching perspective, younger FL learners will benefit from an explicit approach, especially the keyword method (Dolean \& Dolghi, 2016). They should learn basic level words (Cameron, 2001) and words that are appealing to them (Szpotowicz, 2009). However, learning different aspects of the word will depend on the child's maturation (Cameron, 2001) and their general knowledge (Piquer Pizir, 2008). Also, in EFL, the low orthographic transparency of English (Cameron, 2001) and the difference in the sound system between the child's mother tongue and English (Szpotowicz, 2009) may affect the development of some aspects of vocabulary.

Vocabulary learning in an FL may be especially difficult for learners with dyslexia because they have weaker short-term phonological memory; thus, they process and store information less efficiently (Kormos, 2017). They may have difficulties with speed, retrieval, and in providing substitutions (semantic, orthographic or phonological). Consequently, their vocabulary size may be significantly smaller than the typical learners' (Kormos \& Smith, 2012).

Numerous studies have reported difficulties in learning new words in EFL by learners with dyslexia. These difficulties included inaccurate repeating of a new word after the teacher (Kormos \& Kontra, 2008), effective memorisation of new words (Kormos \& Kontra, 2008; Kormos \& Mikó, 2010 in Kormos \& Smith, 2012; Sarkadi, 2008), inaccurate spelling and pronunciation, and mixing up similarly looking and sounding words (Sarkadi, 2008). Learners with dyslexia may particularly struggle with longer words, abstract nouns, and adjectives (Kormos \& Kontra, 2008). They may also struggle to acquire more advanced lexical expressions and socio-pragmatic language concepts such as idiomatic expressions, humour, jokes, homonyms, homographs, or metaphors (Schneider \& Crombie, 2003). Learning new vocabulary is also tiresome for learners with dyslexia (Sarkadi, 2008), and it will depend on their first language vocabulary size (Kormos \& Smith, 2012).

Since learners with dyslexia find incidental learning particularly difficult due to weaker phonological processing (Kormos \& Smith, 2012), one of the 
most frequently recommended approaches in teaching foreign languages to learners with dyslexia is the MSL approach. It was developed by Sparks et al. (1991) on the principles of the remedial approach to learning difficulties in L1, that is, the Orton-Gillingham approach (Gillingham \& Stillman, 1997). The Sparks et al.'s model was later modified by Schneider and Ganschow (2000) by adding the dynamic assessment, which is a method of in-classroom assessment that facilitates student learning by focusing on the process rather than its outcomes.

The MSL approach has had many adaptations (e.g. Kałdonek-Crnjaković \& Fišer, forthcoming; Kormos \& Smith, 2012; Nijakowska, 2010; Schneider \& Crombie, 2003), but its core elements are:

1. explicit instruction of language patterns, including a contrastive analysis of L1 and L2 patterns for similarities and differences, and a synthetic approach to enrich vocabulary activities;

2. a structured presentation of language concepts, which is a logical and gradual introduction of language concepts, where a more complex idea is built on an easier one, concerning the previously learned information;

3. multisensory practice, that is the simultaneous use of the visual, auditory, and kinaesthetic and tactile channels;

4. a metacognitive approach to raise metalinguistic knowledge involves encouraging the learner to discover independently how language works and how they can self-correct and monitor their learning process; and

5. overlearning, that is, frequent revision of the learning material.

Many studies have evidenced its positive effect in developing FL skills in English (Kałdonek-Crnjaković, 2015; Nijakowska, 2008, 2010; Pfenninger, 2015; Sarkadi, 2008), German (Schneider, 1999), and Spanish (Sparks \& Ganschow, 1993; Sparks et al., 1992, 1998). Structured instruction with explicit teaching language rules in a multisensory way with frequent revision opportunities was also reported beneficial by learners with dyslexia (Kałdonek-Crnjaković, 2017; Kormos, Csizér \& Sarkadi, 2009).

However, empirical research that reports on the effect of the MSL approach in teaching semantic aspects of vocabulary in an FL to learners with dyslexia is scarce. Sparks and Ganschow (1993) and Sparks et al. (1992, 1998) investigated vocabulary learning in a multisensory and structured way in college students with dyslexia in Spanish as a foreign language, whereas Pfenninger (2015) in younger learners of English as the third language. The findings of these studies reported that the participants with dyslexia improved their vocabulary, especially receptive knowledge. 


\section{THE PRESENT STUDY}

\subsection{The aim and research questions}

The study was a longitudinal case study in teaching conditions that lasted for two years and seven months. It aimed at investigating the effect of the MSL approach in vocabulary development in EFL of two learners with dyslexia, who were of different ages. The focus was on productive vocabulary knowledge. This study sought to answer the following research questions (RQs):

1. To what extent will each participant benefit from the MSL approach in developing vocabulary in EFL?

2. Will the age of the participants be a salient factor regarding the effect of the MSL approach?

Based on the previous findings, it can be hypothesised for RQ 1 that both participants will benefit from instruction based on the MSL approach (see, for example, Kałdonek-Crnjaković, 2015; Nijakowska, 2008; Pfenninger, 2015). However, the age of the participant, namely his cognitive maturity, will be salient (RQ 2). Lower retrieval of newly learned vocabulary will be in the child participant (see, Kałdonek-Crnjaković, 2015).

\subsection{Participants}

Two male EFL learners with dyslexia, whose mother tongue was Croatian, participated in the study.

They differed in age. The first participant (P1) was ten years and eight months old when the study began, and 13 years and three months old when the study finished. The second participant (P2) was 21 years and eight months old when the study started, and 24 years and three months old when the study finished.

The participants were diagnosed with dyslexia in their mother tongue by a speech and language specialist and psychologist. The statement for both participants claimed the uneven cognitive profile typical for individuals with dyslexia, that is reading and spelling difficulties and above-average non-verbal intelligence. The difficulties in spelling were also manifested in English, which was revealed in the assessment of English language proficiency conducted prior to the instruction.

Both participants learned EFL in primary and secondary school, where traditional foreign language teaching methods were used. P2 also had contact with English at the university, where he was expected to read in English for the subjects he was studying. Both participants also learned other foreign languages at the time of the instruction; P1 learned German, whereas P2 learned Italian. 
P1's EFL knowledge was assessed against the national curriculum for primary school (Ministry of Science, Education and Sports, 2006). The scope of the assessment included the English language skills that were taught in the first four years of primary school. The results of the test showed that P1's English skills were at the level of year one, which suggested a three-year delay in reference to the curriculum requirements.

The academic version of the International English Language Testing System was used to measure P2's English language proficiency. The test results suggested that P2's English language skills were strong intermediate.

\subsection{Procedure}

The participants received MSL instruction in three sessions: session one lasted ten weeks, session two 15 weeks, and session three was 20 weeks long.

After each session, a break followed during which the participants did not receive any MSL instruction. The duration of the break varied depending on the participants' school timetable. A four-week break followed session one and three, and the break after session two lasted six weeks.

The participants attended one lesson per week, during which they learned the meaning of between two to five new words or phrases (referred to as 'a phrase' later in the text). Lessons were taught by the author of this paper (referred to as 'the teacher' later in the text).

The new vocabulary was taught according to the MSL approach. Phrases were introduced in isolation, following the recommendation in the literature (File \& Adams, 2010). Participants learned the definition of the phrase in English, its synonyms and antonyms, and translated it into Croatian; the phrase was also presented in a sentence. Pronunciation of the phrase was also explicitly approached.

The teacher discussed different memorisation strategies with participants, which included, for example, flashcards or acting out the phrase. The new phrase was revised on many occasions during the lesson, including its pronunciation. For example, participants wrote sentences with the phrase on their own or did gap-filling exercises. The knowledge about the new phrase was cumulated at the end of the lesson. Participants pronounced the phrase and, depending on the phrase, gave its definition in English, synonym, antonym, translated the phrase into Croatian, or presented it in a meaningful sentence.

New phrases were introduced in a structured way. The introduction of new phrases was done in accordance with the participant's current proficiency level and his learning needs. For example, P1 first learned phrases that were prescribed by the curriculum for year one of primary school. In the first session, P2 learned a more common vocabulary, whereas, in the final session, he attempted more abstract vocabulary. 
Each lesson began with an assessment of the retrieval of the vocabulary learned in the previous lesson. Productive knowledge of vocabulary was assessed in a controlled context. Participants had to come up with the correct phrase, including pronouncing it correctly, upon its definition or explanation in English, or its translation into Croatian. In the case of P1, the assessment also took form of a dialogue in English, where P1 was supposed to respond to a question, for example, to such questions as How are you?

Participants had unlimited time to recall the phrase. If the participant did not recall the phrase, it was taught again in that lesson. The maximum time the phrase was retaught (i.e. overlearning) was five times, that is, five consecutive lessons. The maximum time of overlearning was decided considering the minimum time of exposure for successful recall suggested in the literature (Nation, 1990; Peters, 2014). Regarding the findings by Webb (2007), i.e. ten learning occasions of a new word were not enough to learn all its aspects, it was assumed that five learning events would be enough to acquire the meaning of the phrase.

The retrieval of the phrases that were acquired in a session was assessed after the break that followed that session, and additionally after the consecutive sessions and breaks. All the phrases acquired in session one, two, and three were additionally assessed for retrieval 16 months after session three and the break that followed it.

\subsection{Analysis}

A mixed-method approach was applied. The quantitative data, presented as figures and percentage, included the phrases learned, acquired and retrieved, the time of overlearning, and the relation between the time of overlearning and the overall retrieval rate. The qualitative data included examples of the phrases the participants were learning, managed or failed to acquire and retrieve.

The following codes were used for the assessment of retrieval of the vocabulary:

- TEST_1_a - assessment of the phrases acquired in session one after the break that followed session one (i.e., the first assessment of the phrases acquired in session one);

- TEST_1_b - assessment of the phrases acquired in session one after the break that followed session two (i.e., the second assessment of the phrases acquired in session one);

- TEST_1_c - assessment of the phrases acquired in session one after the break that followed session three (i.e., the third assessment of the phrases acquired in session one); 
- TEST_1_d - assessment of the phrases acquired in session one 16 months after the break that followed session three (i.e., the fourth assessment of the phrases acquired in session one);

- TEST_2_a - assessment of the phrases acquired in session two after the break that followed session two (i.e., the first assessment of the phrases acquired in session two);

- TEST_2_b - assessment of the phrases acquired in session two after the break that followed session three (i.e., the second assessment of the phrases acquired in session two);

- TEST_2_c - assessment of the phrases acquired in session two 16 months after the break that followed session three (i.e., the third assessment of the phrases acquired in session two);

- TEST_3_a - assessment of the phrases acquired in session three after the break after session three (i.e., the first assessment of the phrases acquired in session three);

- TEST_3_b - assessment of the phrases acquired in session three 16 months after the break that followed session three (i.e., the second assessment of the phrases acquired in session three).

To assess long-term retrieval, and thus the long-term effect of the instruction, it was necessary to make a distinction between the assessment during the time of instruction and the assessment that was conducted 16 months after session three and the break that followed it. TEST_1_a, TEST_1_b, TEST_1_c, TEST_2_a, TEST_2_b, and TEST_3_a, which were the assessments conducted during the time of instruction, will be referred to as 'the initial evaluation', whereas TEST_1_d, TEST_2_c, and TEST_3_b, which were the assessments conducted 16 months after the instruction finished, will be referred to as 'the final evaluation' later in the text. The average per cent of retrieval was calculated for both evaluations.

The results will be discussed separately for each participant and each session in the following order:

1. the aggregate of the phrases that the participant was learning;

2. the number and per cent of the acquired phrases (considering the maximum time of overlearning);

3. examples of acquired phrases and phrases that the participant did not acquire within the maximum time of overlearning;

4. the number and per cent of the phrases that required no overlearning, one-, two-, three-, and four-time overlearning; examples of phrases are provided; and

5. the number and per cent of the retrieved phrases in all the assessments. 


\section{RESULTS}

\subsection{Participant 1 (P1)}

In session one, P1 was learning 26 phrases, of which he acquired $22(85 \%)$. It included greetings, names of some colours (e.g. orange, green, pink), asking for one's name and age, telling his name and age; he also acquired water and thank you. P1 did not acquire the following phrases: brown, purple, white, and yellow.

Most of the phrases required two-time overlearning (9; 41\%). It included phrases such as black, blue, good evening, good night, My name is ..., pink, sea, thank you, and to see. Four phrases were acquired immediately $(18 \%$; good morning, hello, red, and water); three needed three-time overlearning (14\%; green, grey, orange); and six required four-time overlearning $(27 \%$; good afternoon, How are you?, How old are you?, I'm fine, I'm ten, and What's your name?).

In TEST_1_a, P1 retrieved 20 phrases, which constituted 91\% of the vocabulary acquired in session one. The phrases sea and to see were not retrieved; these two phrases required two-time overlearning. The results of TEST_1_b, TEST_1_c were the same as of TEST_1_a. In TEST_1_d, P1 retrieved 18 phrases, which was $82 \%$ of the acquired vocabulary; nine percentage points lower than in the previous tests. He did not retrieve two additional phrases: good afternoon, which required four-time overlearning, and good evening, which needed two-time overlearning.

The average retrieval rate for the vocabulary in session one that was acquired immediately and required three-time overlearning was $100 \%$, whereas for two-time overlearning it was $75 \%$ and $96 \%$ for four-time overlearning.

The summary of the results for vocabulary acquisition in session one by $\mathrm{P} 1$ is presented in Table 1. 
Table 1. Vocabulary acquisition in session one for P1

\begin{tabular}{|l|l|l|}
\hline 1 & Number (no.) of phrases P1 was learning & 26 \\
\hline 2 & No. and per cent of the phrases acquired & $22 ; 85 \%$ \\
\hline 3 & No. and per cent of the phrases that were not acquired & $4 ; 15 \%$ \\
\hline 4 & No. and per cent of the phrases that did not need overlearning & $4 ; 18 \%$ \\
\hline 5 & No. and per cent of the phrases that needed two-time overlearning & $9 ; 41 \%$ \\
\hline 6 & No. and per cent of the phrases that needed three-time overlearning & $3 ; 14 \%$ \\
\hline 7 & No. and per cent of the phrases that needed four-time overlearning & $6 ; 27 \%$ \\
\hline 8 & No. and per cent of the phrases retrieved in TEST_1_a & $20 ; 91 \%$ \\
\hline 9 & No. and per cent of the phrases retrieved in TEST_1_b & $20 ; 91 \%$ \\
\hline 10 & No. and per cent of the phrases retrieved in TEST_1_c & $20 ; 91 \%$ \\
\hline 11 & No. and per cent of the phrases retrieved in TEST_1_d & $18 ; 82 \%$ \\
\hline 12 & The average retrieval rate for the phrases that did not need overlearning & $100 \%$ \\
\hline 13 & The average retrieval rate for the phrases that needed two-time overlearning & $75 \%$ \\
\hline 14 & The average retrieval rate for the phrases that needed three-time overlearning & $100 \%$ \\
\hline 15 & The average retrieval rate for the phrases that needed four-time overlearning & $96 \%$ \\
\hline
\end{tabular}

In session two, P1 acquired 34 phrases out of 35 he was learning (97\%); the phrase that he did not acquire was he isn't. Most of the phrases required one-time overlearning (19;56\%), including words such as big, bus, I don't like, and swim. Nine phrases were acquired immediately (26\%; e.g., dog, eleven, and this is); three phrases required two-time overlearning (9\%; e.g., I don't have, she/he has, reading), and three phrases needed three-time overlearning (9\%; e.g., boat, I have got, I haven't got).

In TEST_2_a, P1 retrieved 27 out of 34 phrases (79.5\%). The phrases that were not retrieved were all the phrases that required three-time overlearning (boat, I have got, I haven't got) and four one-time overlearning phrases (21\%; bag, egg, I live, ill). In TEST_2_b, P1 retrieved $76.5 \%$ of the acquired vocabulary in session two (26 phrases), which was three percentage points lower than in the previous test. The additional phrase that he did not retrieve was she/he has, which required two-time overlearning (33\% of the two-time overlearning phrases). In TEST_2_c, P1 retrieved 68\% of the acquired vocabulary in session two (23 phrases), which was eight and a half percentage points less than in the previous assessment (TEST_2_b) and 11.5 percentage points lower than in the first assessment (TEST_2_a). The phrases that he did not retrieve were the phrases that were not retrieved in the previous tests and one more phrase that required one-time overlearning, that is, I don't like (26\% of the one-time overlearning phrases), and two more phrases that required twotime overlearning: I don't have and reading (i.e., all the phrases that required two-time overlearning). 
The average retrieval rate for the vocabulary in session two that was acquired immediately was $100 \%$, for one-time overlearning it was $77 \%$, for two-time overlearning it was $56 \%$, and $0 \%$ for three-time overlearning.

The summary of the results for vocabulary acquisition in session two by P1 is presented in Table 2.

Table 2. Vocabulary acquisition in session two for P1

\begin{tabular}{|l|l|l|}
\hline 1 & No. of phrases P1 was learning & 35 \\
\hline 2 & No. and per cent of the phrases acquired & $34 ; 97 \%$ \\
\hline 3 & No. and per cent of the phrases that were not acquired & $1 ; 3 \%$ \\
\hline 4 & No. and per cent of the phrases that did not need overlearning & $9 ; 26 \%$ \\
\hline 5 & No. and per cent of the phrases that needed one-time overlearning & $19 ; 56 \%$ \\
\hline 6 & No. and per cent of the phrases that needed two-time overlearning & $3 ; 9 \%$ \\
\hline 7 & No. and per cent of the phrases that needed three-time overlearning & $3 ; 9 \%$ \\
\hline 8 & No. and per cent of the phrases that needed four-time overlearning & 0 \\
\hline 9 & No. and per cent of the phrases retrieved in TEST_2_a & $27 ; 79.5 \%$ \\
\hline 10 & No. and per cent of the phrases retrieved in TEST_2_b & $26 ; 76.5 \%$ \\
\hline 11 & No. and per cent of the phrases retrieved in TEST_2_c & $23 ; 68 \%$ \\
\hline 12 & The average retrieval rate for the phrases that did not need overlearning & $100 \%$ \\
\hline 13 & The average retrieval rate for the phrases that needed one-time overlearning & $77 \%$ \\
\hline 14 & The average retrieval rate for the phrases that needed two-time overlearning & $56 \%$ \\
\hline 15 & The average retrieval rate for the phrases that needed three-time overlearning & $0 \%$ \\
\hline
\end{tabular}

In session three, $\mathrm{P} 1$ was learning 39 phrases of which he acquired 38 (97.5\%); he did not acquire shoulder. Most of the phrases required one-time overlearning (16; 42\%), which included such as angry, butter, new, and snow. Twelve phrases were acquired immediately (31.5\%; e.g., bike, ice, to buy), whereas seven required two-time overlearning (18.5\%; e.g., bored, hair, sugar), one three-time overlearning ( $3 \%$; tired), and two four-time overlearning ( $5 \%$; difficult, teeth).

In TEST_3_a, P1 retrieved 24 phrases, which constituted $63 \%$ of the acquired vocabulary. The phrases that were not retrieved were all the phrases that required two-, three-, and four-time overlearning (see above for examples), and four phrases that needed one-time overlearning $(25 \%$; cold, hot, lazy, new). In TEST_3_b, P1 retrieved 55\% of the acquired vocabulary (21 phrases), that is eight percentage points less than in the previous test. The three additional phrases that were not retrieved were the phrases that required one-time overlearning: angry, eye, and sleepy ( $44 \%$ of the one-time overlearning phrases).

The average retrieval rate for the vocabulary in session three that was acquired immediately was $100 \%$, for one-time overlearning it was $65.5 \%$, and for two-, three-, and four-time it was $0 \%$. 
The summary of the results for vocabulary acquisition in session three by $\mathrm{P} 1$ is presented in Table 3.

Table 3. Vocabulary acquisition in session three for P1

\begin{tabular}{|l|l|l|}
\hline 1 & No. of phrases P1 was learning & 39 \\
\hline 2 & No. and per cent of the phrases acquired & $38 ; 97.5 \%$ \\
\hline 3 & No. and per cent of the phrases that were not acquired & $1 ; 2.5 \%$ \\
\hline 4 & No. and per cent of the phrases that did not need overlearning & $12 ; 31.5 \%$ \\
\hline 5 & No. and per cent of the phrases that needed one-time overlearning & $16 ; 42 \%$ \\
\hline 6 & No. and per cent of the phrases that needed two-time overlearning & $7 ; 18,5 \%$ \\
\hline 7 & No. and per cent of the phrases that needed three-time overlearning & $1 ; 3 \%$ \\
\hline 8 & No. and per cent of the phrases that needed four-time overlearning & $2 ; 5 \%$ \\
\hline 9 & No. and per cent of the phrases retrieved in TEST_3_a & $24 ; 63 \%$ \\
\hline 10 & No. and per cent of the phrases retrieved in TEST_3_b & $21 ; 55 \%$ \\
\hline 11 & The average retrieval rate for the phrases that did not need overlearning & $100 \%$ \\
\hline 12 & The average retrieval rate for the phrases that needed one-time overlearning & $65.5 \%$ \\
\hline 13 & The average retrieval rate for the phrases that needed two-time overlearning & $0 \%$ \\
\hline 14 & The average retrieval rate for the phrases that needed three-time overlearning & $0 \%$ \\
\hline
\end{tabular}

Overall, P1 was learning 100 phrases out of which he acquired 94. In the initial evaluation, i.e. the assessments conducted during the time of instruction, $\mathrm{P} 1$ retrieved $82 \%$ of the phrases, whereas, in the final evaluation, i.e. the assessments conducted after 16 months the instruction finished, the retrieval was 20 percentage points lower (62\% of the phrases). The overall vocabulary acquisition and retrieval rate for P1 are shown in Table 4.

Table 4. The overall vocabulary acquisition and retrieval rate for P1

\begin{tabular}{|l|l|l|}
\hline 1 & No. of phrases P1 was learning & 100 \\
\hline 2 & No. and per cent of the phrases acquired & $94 ; 94 \%$ \\
\hline 3 & No. and per cent of the phrases that were not acquired & $6 ; 6 \%$ \\
\hline 4 & $\begin{array}{l}\text { Per cent of the phrases retrieved in the initial evaluation (during the time of } \\
\text { instruction) }\end{array}$ & $82 \%$ \\
\hline 5 & Per cent of the phrases retrieved in the final evaluation (after 16 months) & $62 \%$ \\
\hline
\end{tabular}

Regarding the overall retrieval rate and overlearning, P1 retrieved $100 \%$ of the phrases that he acquired without the need for overlearning. He retrieved $72.5 \%$ of the one-time overlearning phrases, $52 \%$ of the two-time overlearning phrases, $44 \%$ of the three-time overlearning phrases, and $64 \%$ of the four-time overlearning phrases. Since the retrieval rate for four-time overlearning phrases was higher than the two- and three-time overlearning phrases, overall, a negative correlation between the time of overlearning and the retrieval rate could not be established. On the other hand, there was a 
negative correlation between the retrieval rate and the time of overlearning considering no need of overlearning, one-, two-, and three-time overlearning. The relationship between the overall retrieval rate and overlearning for P1 is shown in Figure 1.

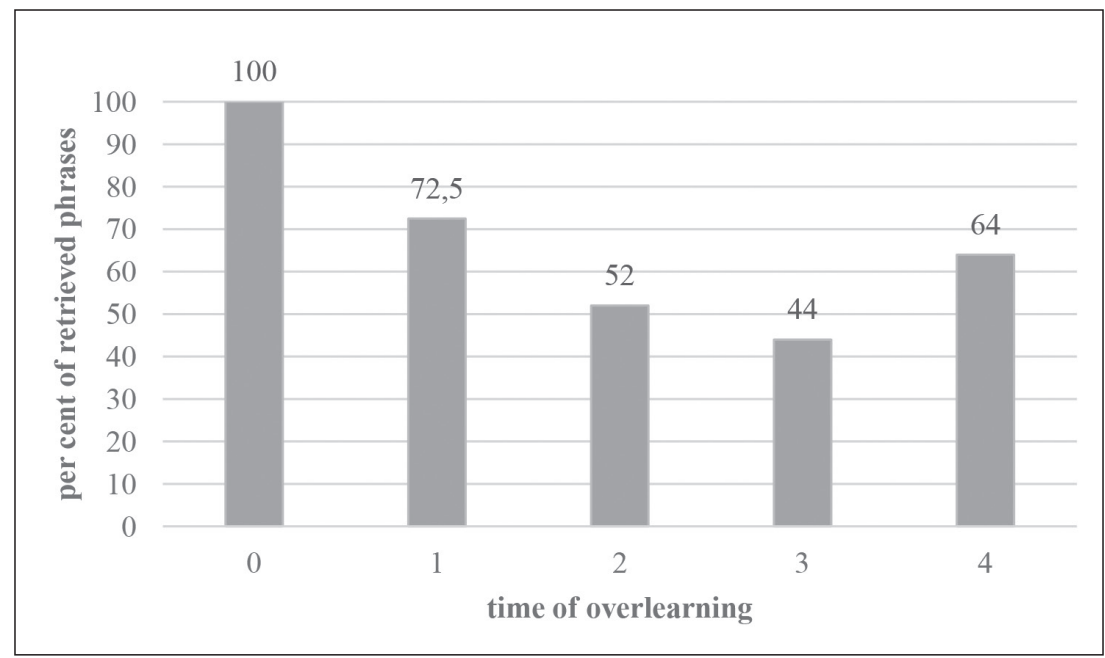

Figure 1. The relation between the time of overlearning and the overall retrieval rate for P1

\subsection{Participant 2 (P2)}

In session one, P2 was learning 13 phrases; he acquired all of them $(100 \%)$. It included words such as paved, reliable, and to contribute. In terms of overlearning, P2 needed a maximum of two times to acquire a phrase. He acquired immediately ten phrases (77\%; e.g., association, to set off, and venue), two phrases needed one-time overlearning (15\%; dissertation, incentive), and one phrase required two-time overlearning $(8 \%$; limb).

In TEST_1_a, P2 retrieved 11 phrases, which constituted $84.5 \%$ of the acquired vocabulary. The phrases that were not retrieved were rigorous, which needed no overlearning, and dissertation, which required one-time overlearning. In TEST_1_b, P2 also retrieved $84.5 \%$ of the acquired vocabulary; however, the phrases that were not retrieved were to set off, which required no overlearning, and limb, which needed two-time overlearning. In TEST_1_c, P2 retrieved $92 \%$ of the acquired vocabulary, which was an improvement of seven and a half percentage points compared to the previous assessments. The phrase that he did not retrieve was incentive, which needed one-time overlearning. The results of TEST_1_d were the same as of TEST_1_c.

The average retrieval rate for the vocabulary in session one that was acquired immediately was $95 \%$, for one-time overlearning it was $62.5 \%$, and for two-time overlearning it was $87.5 \%$. 
The summary of the results for vocabulary acquisition in session one by P2 is presented in Table 5.

Table 5. Vocabulary acquisition in session one for P2

\begin{tabular}{|l|l|l|}
\hline 1 & No. of phrases P2 was learning & 13 \\
\hline 2 & No. and per cent of the phrases acquired & $13 ; 100 \%$ \\
\hline 3 & No. and per cent of the phrases that were not acquired & $0 ; 0 \%$ \\
\hline 4 & No. and per cent of the phrases that did not need overlearning & $10 ; 77 \%$ \\
\hline 5 & No. and per cent of the phrases that needed one-time overlearning & $2 ; 15 \%$ \\
\hline 6 & No. and per cent of the phrases that needed two-time overlearning & $1 ; 8 \%$ \\
\hline 7 & No. and per cent of the phrases retrieved in TEST_1_a & $11 ; 84.5 \%$ \\
\hline 8 & No. and per cent of the phrases retrieved in TEST_1_b & $11 ; 84.5 \%$ \\
\hline 9 & No. and per cent of the phrases retrieved in TEST_1_c & $12 ; 92 \%$ \\
\hline 10 & No. and per cent of the phrases retrieved in TEST_1_d & $12 ; 92 \%$ \\
\hline 11 & The average retrieval rate for the phrases that did not need overlearning & $95 \%$ \\
\hline 12 & The average retrieval rate for the phrases that needed one-time overlearning & $62.5 \%$ \\
\hline 13 & The average retrieval rate for the phrases that needed two-time overlearning & $87.5 \%$ \\
\hline
\end{tabular}

In session two, P2 was learning 27 phrases; he acquired all of them $(100 \%)$. It included words such as bald, curious, and to resemble. In terms of overlearning, P2 needed a maximum of one time to acquire a phrase. He acquired immediately 16 phrases (63\%; e.g., cast, dubbed, and hideous), and 11 phrases needed one-time overlearning (37\%; e.g., luxurious, product endorsement, and to look up to).

In TEST_2_a, P2 retrieved 26 phrases, which constituted $96 \%$ of the acquired vocabulary. The phrases that were not retrieved was elective, which required one-time overlearning. In TEST_2_b he retrieved $85 \%$ of the acquired vocabulary ( 23 phrases), which was a drop of 11 percentage points compared to the previous assessment. The phrases that were not retrieved included one phrase that did not need overlearning (cast), and three phrases that required one-time overlearning (elective, product endorsement, and to reconcile). In TEST_2_c, P2 retrieved 24 phrases (89\%), which was an improvement of four percentage points compared to the previous assessment, but seven percentage points lower than in the first assessment (TEST_2_a). The phrases that he did not retrieve were the one-time overlearning phrases that he did not retrieve in the previous assessment (TEST_2_b).

The average retrieval rate for the vocabulary in session two that was acquired immediately was $98 \%$, and $79 \%$ for one-time overlearning.

The summary of the results for vocabulary acquisition in session two by P2 is presented in Table 6 . 
Table 6. Vocabulary acquisition in session two for P2

\begin{tabular}{|l|l|l|}
\hline 1 & No. of phrases P2 was learning & 27 \\
\hline 2 & No. and per cent of the phrases acquired & $27 ; 100 \%$ \\
\hline 3 & No. and per cent of the phrases that were not acquired & $0 ; 0 \%$ \\
\hline 4 & No. and per cent of the phrases that did not need overlearning & $16 ; 63 \%$ \\
\hline 5 & No. and per cent of the phrases that needed one-time overlearning & $11 ; 37 \%$ \\
\hline 6 & No. and per cent of the phrases retrieved in TEST_2_a & $26 ; 96 \%$ \\
\hline 7 & No. and per cent of the phrases retrieved in TEST_2_b & $23 ; 85 \%$ \\
\hline 8 & No. and per cent of the phrases retrieved in TEST_2_c & $24 ; 89 \%$ \\
\hline 9 & The average retrieval rate for the phrases that did not need overlearning & $98 \%$ \\
\hline 10 & The average retrieval rate for the phrases that needed one-time overlearning & $79 \%$ \\
\hline
\end{tabular}

In session three, P2 was learning 30 phrases; he acquired all of them $(100 \%)$. It included words such as feasible, obstacles, and sustainability. In terms of overlearning, P2 needed a maximum of two times to acquire a phrase. He acquired immediately 19 phrases (63\%; e.g., comprehensive, prey, and retail), nine phrases needed one-time overlearning (30\%; e.g., extinction, scattered, and sustainable), and two required two-time overlearning (7\%; sustainability, and to encompass).

In TEST_3_a, P2 retrieved 27 phrases, which constituted $90 \%$ of the acquired vocabulary. The phrases that were not retrieved were the phrases that required two-time overlearning (sustainability and to encompass), and nocturnal, which needed one-time overlearning. In TEST_3_b, P2 retrieved 26 phrases, which was $87 \%$ of the acquired vocabulary; it was three percentage points lower compared to the previous assessment. The phrases that P2 did not retrieve were the phrases that he had not retrieved in the previous assessment and one additional phrase, which required one-time overlearning (commodity).

The average retrieval rate for the vocabulary in session three that was acquired immediately was $100 \%$, for one-time overlearning it was $78 \%$, and $0 \%$ for two-time overlearning.

The summary of the results for vocabulary acquisition in session three by $\mathrm{P} 2$ is presented in Table 7. 
Table 7. Vocabulary acquisition in session three for P2

\begin{tabular}{|l|l|l|}
\hline 1 & No. of phrases P2 was learning & 30 \\
\hline 2 & No. and per cent of the phrases acquired & $30 ; 100 \%$ \\
\hline 3 & No. and per cent of the phrases that were not acquired & $0 ; 0 \%$ \\
\hline 4 & No. and per cent of the phrases that did not need overlearning & $19 ; 63 \%$ \\
\hline 5 & No. and per cent of the phrases that needed one-time overlearning & $9 ; 30 \%$ \\
\hline 6 & No. and per cent of the phrases that needed two-time overlearning & $2 ; 7 \%$ \\
\hline 7 & No. and per cent of the phrases retrieved in TEST_3_a & $27 ; 90 \%$ \\
\hline 8 & No. and per cent of the phrases retrieved in TEST_3_b & $26 ; 87 \%$ \\
\hline 9 & The average retrieval rate for the phrases that did not need overlearning & $100 \%$ \\
\hline 10 & The average retrieval rate for the phrases that needed one-time overlearning & $78 \%$ \\
\hline 11 & The average retrieval rate for the phrases that needed two-time overlearning & $0 \%$ \\
\hline
\end{tabular}

Overall, P2 was learning 70 phrases, of which he acquired all (100\%). In the initial evaluation, i.e. the assessments conducted during the time of instruction, and in the final evaluation, i.e. the assessments 16 months after the instruction finished, P2 retrieved $89 \%$ of the phrases. The overall vocabulary acquisition and retrieval rate for P2 are shown in Table 8.

Table 8. The overall vocabulary acquisition and retrieval rate for $P 2$

\begin{tabular}{|l|l|l|}
\hline 1 & No. of phrases P1 was learning & 70 \\
\hline 2 & No. and per cent of the phrases acquired & $70 ; 100 \%$ \\
\hline 3 & No. and per cent of the phrases that were not acquired & $0 ; 0 \%$ \\
\hline 4 & $\begin{array}{l}\text { Per cent of the phrases retrieved in the initial evaluation (during the time of } \\
\text { instruction) }\end{array}$ & $89 \%$ \\
\hline 5 & $\begin{array}{l}\text { Per cent of the phrases retrieved in the final evaluation (after the period of 16 } \\
\text { months) }\end{array}$ & $89 \%$ \\
\hline
\end{tabular}

Considering the overall retrieval rate and overlearning, P2 retrieved 98\% of the phrases that he acquired without the need for overlearning, $73 \%$ of the one-time overlearning phrases, and $44 \%$ of the two-time overlearning phrases. Therefore, there was a negative correlation between the overlearning and the retrieval rate; the retrieval rate was lower for the phrases that required more overlearning. The relationship between the overall retrieval rate and overlearning for P2 is shown in Figure 2. 


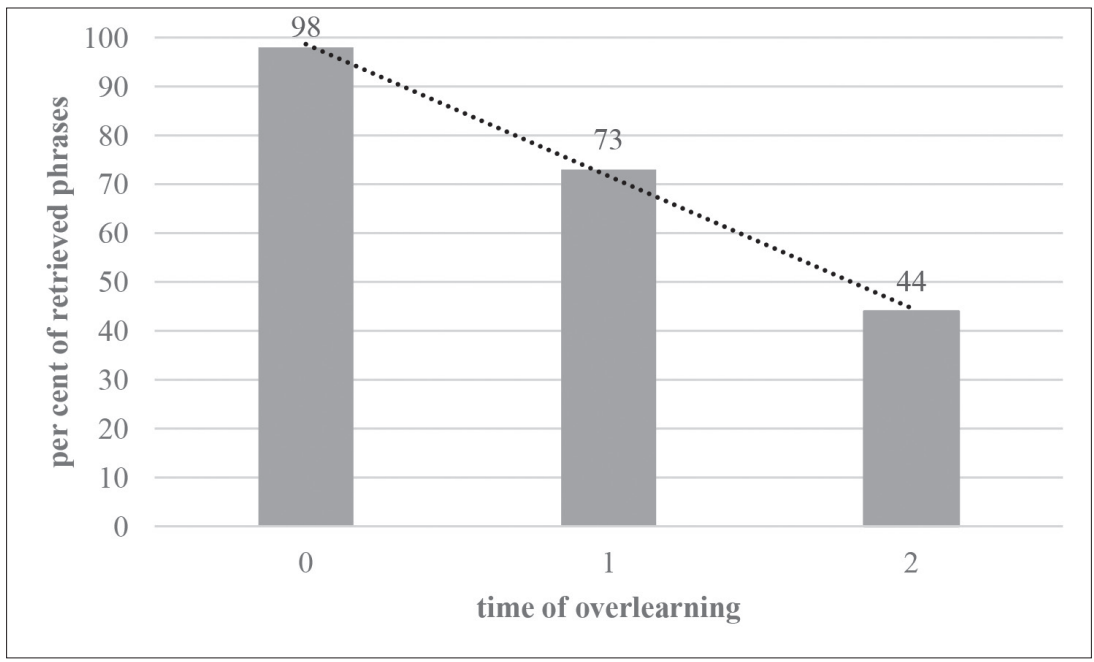

Figure 2. The relation between the time of overlearning and the overall retrieval rate for $P 2$

\section{DISCUSSION}

This study aimed to examine the effect of the MSL approach in vocabulary development in EFL in learners with dyslexia of different ages. The focus was on productive vocabulary knowledge. The first research question was to investigate the extent to which each participant benefited from the MSL approach in learning new vocabulary in EFL. The second research question sought an answer to whether the difference in age (i.e. the age factor) would matter regarding the effect of MSL instruction in vocabulary development in EFL.

The results suggest that both participants benefited from MSL instruction with a long-term effect. Both of them learned many new phrases. The child participant (P1) learned 100, and the adult participant (P2) learned 70 new phrases. They successfully recalled the majority of the vocabulary they had learned one year and a half after the instruction was finished; P1 retrieved $62 \%$, and P2 $89 \%$ of the acquired phrases. Hence, these results corroborate the previous findings on the effect of the MSL approach in teaching FL skills to learners with dyslexia (Kałdonek-Crnjaković, 2015; Nijakowska, 2008, 2010; Pfenninger, 2015; Sarkadi, 2008; Schneider, 1999; Sparks \& Ganschow, 1993; Sparks et al., 1992, 1998).

Furthermore, vocabulary acquisition improved in both participants since they acquired new phrases at a faster rate. The number of phrases that P1 did not need to overlearn grew gradually during the sessions $(18 \%, 26 \%$ and $31.5 \%$, respectively; as shown in the fourth row in Tables 1, 2, and 3 above). Moreover, in the first session, P1 needed at least two-time overlearning 
to acquire $41 \%$ of the phrases, and $27 \%$ of the phrases required four-time overlearning (as shown in rows five and seven in Table 1 above), whereas in session two and three most of the phrases needed just one-time overlearning ( $56 \%$ and $42 \%$, respectively; as shown in row five in Tables 2 and 3 above). Finally, the number of phrases that P1 failed to acquire decreased from four in the first session (15\%; as shown in row three in Table 1 above) to one in session two and three (3\% and 2.5\%, respectively; as shown in row three in Tables 2 and 3 above). Regarding the performance of P2, the aggregate number of overlearning dropped from two times in session one to one time in sessions two and three. There was a similar percentage of the phrases in all three sessions that did not require overlearning yet with a decreasing tendency $(77 \%, 63 \%$, and $63 \%$, respectively; as shown in row four in Tables 5,6 , and 7 above).

However, the adult participant (P2) benefited more from the instruction. Hence, it can be concluded that the age factor is salient regarding the effect of the MSL approach, which confirms what was initially hypothesised.

In the final evaluation, the difference in retrieval rate between the participants was significant; it was 27 percentage points (see Figure 3 below). Moreover, the retrieval rate of the phrases in consecutive sessions dropped in the case of P1. In the final evaluation of the phrases acquired in session one, $\mathrm{P} 1$ retrieved $82 \%$ of the phrases, $68 \%$ in session two, and $55 \%$ in session three (as shown in row 11 in Tables 1 and 2, and in row 10 in Table 3 above). The difference between the retrieval of the phrases acquired in session one and session three was significant; it was 27 percentage points.

$\mathrm{P} 2$, on the other hand, retrieved the phrases of each session at a relatively same rate $(92 \%, 89 \%$, and $87 \%$, respectively; as shown in row ten in Table 5 , and in row eight in Table 6 and 7 above). In addition, as shown in Figure 3 below, the difference between the retrieval rate in the initial and final evaluation was greater in the case of $\mathrm{P} 1$; it was 20 percentage points, whereas there was no difference in retrieval rate in the case of P2. The overall performance of P1 and P2 regarding the retrieval rate in the initial and final evaluation is presented comparatively in Figure 3. 


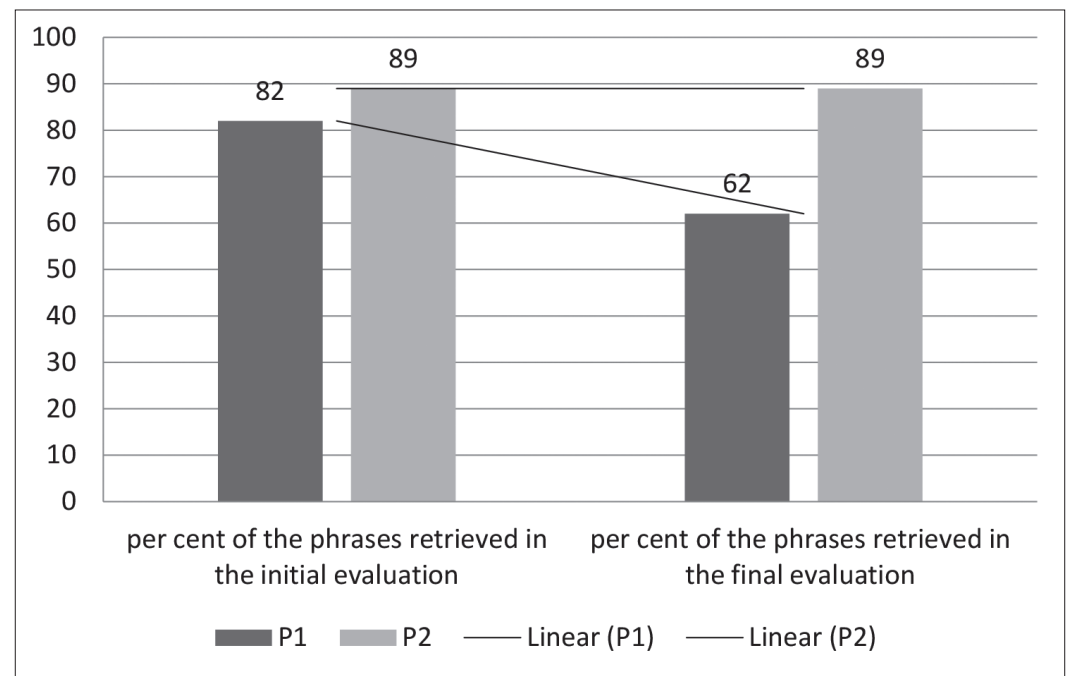

Figure 3. The comparison of the overall performance of $P 1$ and $P 2$ regarding the retrieval rate in the initial and final evaluation

P2 also learned new vocabulary faster as he required less overlearning; he needed the maximum of two-time overlearning, and only for three phrases (4\%). On the other hand, P1 needed the overlearning of two times for 19 phrases (19\%), three times for seven phrases (7\%), and four times for eight phrases ( $8 \%$ ). Also, P1 did not need overlearning for only $25 \%$ of the phrases, compared with $64 \%$ in the case of P2; there was a difference of 39 percentage points. The relation between the need for overlearning and the retrieval rate for both participants is presented in Figure 4.

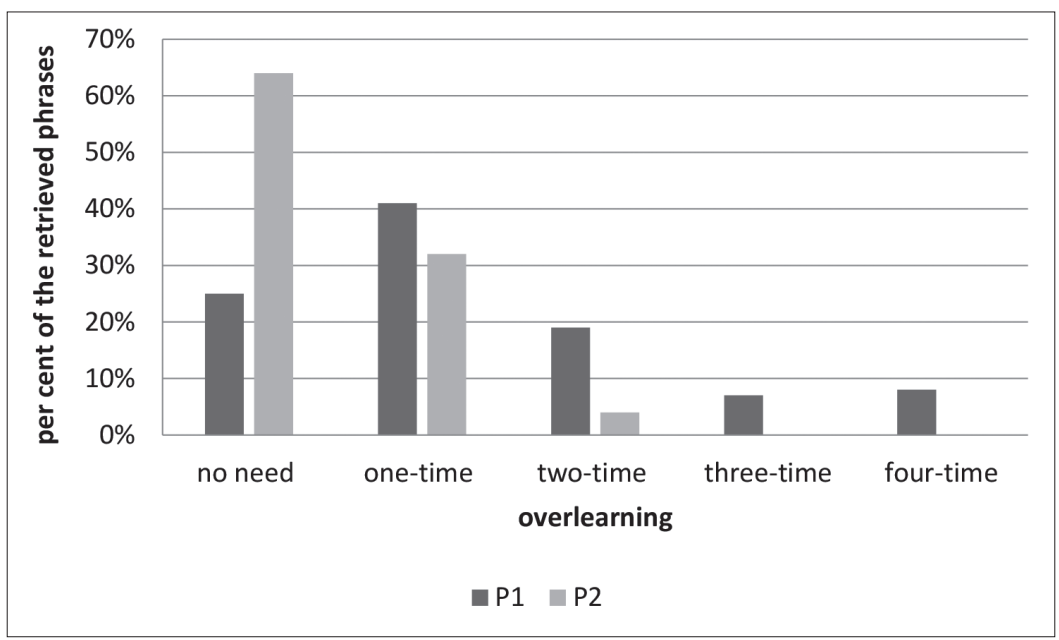

Figure 4. The need for overlearning and the retrieval rate in P1 and P2 
$\mathrm{P} 1$, however, needed less overlearning in consecutive sessions. In session one, he needed three-time overlearning for $14 \%$ of the phrases (as shown in row six in Table 1 above), whereas in session three for 3\% (as shown in row seven in Table 3 above). As to four-time overlearning, P1 needed it for $27 \%$ of the phrases in session 1 (as shown in row seven in Table 1 above), and only for $5 \%$ in session 3 (as shown in row eight in Table 3 above).

It is also noteworthy that the retrieval rate for the phrases that did not require overlearning and for one-time overlearning phrases were similar in both participants; $100 \%$ for P1 and $98 \%$ for P2 for the phrases that did not need overlearning, and for one-time overlearning phrases $72.5 \%$ and $73 \%$, respectively (as shown in Figure 1 and 2 above).

The acquisition and long-term retrieval in the case of $\mathrm{P} 1$ were affected by the complexity and frequency of the phrase. For example, P1 did not succeed in acquiring less common phrases such as purple or shoulder, and in the final evaluation he did not retrieve more complex and longer phrases with difficult pronunciation, such as I don't have, reading, and teeth. In addition, in session one, P1 was learning the vocabulary envisaged by the scheme of work in year one and two of primary school, which included common phrases such as greetings or the names of colours. In contrast, in consecutive sessions, many phrases were from the scheme of work of the year he was attending; they included parts of the body, food, or adjectives expressing feelings.

However, it needs to be acknowledged that P1 had more opportunities to be exposed to session one phrases, if considered that assessments provided additional overlearning (session one phrases were assessed four times whereas session three phrases only two times). Consequently, the retrieval rate for session one phrases after 16 months was significantly higher than for those of session two and three $(82 \%, 68 \%$, and $55 \%$, respectively; as shown in row 11 in Table 1 and 2, and in row ten in Table 3 above).

Similar observations can be made for P2. As shown in rows from seven to ten in Table 5, the additional opportunity for revision in the form of assessment led to an improvement of seven and a half percentage points in retrieval of session one phrases in the third assessment (TEST_1_c; the assessment at the end of instruction) and the fourth assessment (TEST_1_d; the assessment after 16 months) compared to the first two assessments (TEST_1_a and TEST_1_b).

The above findings form some pedagogical implications. Younger learners with dyslexia may need more time to learn more complex and less common vocabulary. Thus, they need more opportunities for revision of such vocabulary. In light of the structured approach, they may also find useful grouping the vocabulary by its complexity and frequency. More common and less complex phrases should be taught first, and less frequent and more advanced structures should be introduced at a later stage of learning 
logically and gradually. However, this implies that learners with dyslexia will be learning vocabulary that was envisaged by the curriculum of lower years.

\section{CONCLUSION}

This longitudinal study of two years and seven months examined the effect of the MSL approach in vocabulary acquisition regarding the age factor and dyslexia. Two Croatian EFL learners with dyslexia who differed in age, a child and an adult, participated in the study.

The study found that learners with dyslexia of different ages can improve their vocabulary in EFL when learning in a multisensory and structured way. Both participants learned many new phrases in English, the majority of which they recalled successfully long after the instruction was over. Still, the adult participant's retrieval rate of the learned phrases was higher, and he needed fewer occasions to learn a phrase; thus, the age factor was salient.

The findings of this study corroborate the results of previous studies that investigated the effect of the MSL approach in teaching EFL to learners with dyslexia (e.g. Nijakowska, 2008, 2010; Pfenninger, 2015; Sarkadi, 2008), including the study that examined the effect of the age factor in spelling development (Kałdonek-Crnjaković, 2015).

This research was a case study, which limits the power of its findings. Future studies of a similar research aim and objectives should involve a larger sample of participants and address different aspects of vocabulary development. Further research should also investigate the effects of the MSL approach in developing various aspects of FL language learning, and include other languages apart from English; so far, the EFL context has been mainly researched.

Undoubtedly, the findings of this study contribute to the literature about the MSL approach in the context of FL teaching to learners with dyslexia. The pedagogical implications of the research stem from the evidence that structured, explicit, and multisensory instruction with frequent revision opportunities is an efficient way of teaching EFL vocabulary to learners with dyslexia of different ages. Such an approach should be incorporated into a regular EFL classroom so that learners with dyslexia have an opportunity to overcome their difficulties that stem from their specific cognitive profile. Ways of including the MSL approach in an FL classroom teaching have been discussed in the literature (see Kałdonek-Crnjaković and Fišer, forthcoming; Kormos \& Smith, 2012; Nijakowska, 2010; Schneider \& Crombie, 2003). 


\section{REFERENCES}

Bao, G. (2015) Task type effects on English as a foreign language learners' acquisition of receptive and productive vocabulary knowledge. System 53, 84-95.

Cameron, L. (2001) Teaching languages to young learners. Cambridge: Cambridge University Press.

Dolean, D. D. and Dolghi, A. (2016) Teaching young FL learners new vocabulary: A comparison between the efficiency of Keyword Method and Total Physical Response. International Journal of English Linguistics 6 (6), 1-7.

File, K. A. and Adams, R. (2010) Should vocabulary instruction be integrated or isolated? TESOL Quarterly 44 (2), 222-249.

Gillingham, A. and Stillman, B. (1997) The Gillingham manual: Remedial training for children with specific disabilities in reading, spelling, and penmanship. (8th edition). Cambridge, USA: Educators Publishing Service.

Hulstijn, J. H. (1997) Mnemonic methods in foreign language vocabulary learning: Theoretical considerations and pedagogical implications. In Coady, J. and Huckin, E. (eds) Second language vocabulary acquisition: A rationale for pedagogy. Cambridge, UK: Cambridge University Press, 203-224.

Jiang, N. (2004) Semantic transfer and development in adult L2 vocabulary acquisition. In Bogaards, P. and Laufer, B. (eds) Vocabulary in a second language: Selection, acquisition and testing. Amsterdam, The Netherlands: John Benjamins, 101-127.

Kałdonek-Crnjaković, A. (2015) Age effect on spelling development in dyslexic Croatian English as a foreign language (EFL) learners. Govor 32 (2), 99-129.

Kałdonek-Crnjaković, A. (2017) Multisensory, structured, metacognitive method in teaching English as a foreign language (EFL) to dyslexic learners: The learner's perspective (a case study from Croatia). Inclusive Practices \& SEN 1, 16-21.

Kałdonek-Crnjaković, A. and Fišer, Z. (forthcoming) Disleksija na nastavi engleskoga kao stranog jezika [Dyslexia in the classroom of English as a foreign language.]. Zagreb, Croatia: Alfa Publishing.

Kormos, J. (2017) The second language processes of students with specific learning difficulties. New York, USA: Routledge.

Kormos, J., Csizér, K. and Sarkadi, Á. (2009) The language learning experiences of students with dyslexia: lessons from an interview study. Innovation in Language Learning and Teaching 3 (2), 115-130.

Kormos, J. and Kontra, E. (2008) Hungarian teachers' perceptions of dyslexic language learners. In Kormos, J. and Kontra, E. (eds) Language learners with special needs. Bristol, UK: Multilingual Matters, 189-213.

Kormos, J. and Smith, A. M. (2012) Teaching languages to students with specific learning differences. Bristol, UK: Multilingual Matters.

Ministry of Science, Education and Sports, The Republic of Croatia. 2006. Nastavni plan i program za osnovnu školu [Curriculum for primary school]. https://www.azoo.hr/ (5.5.2010.).

Nation, I. S. P. (1990) Teaching and learning vocabulary. New York, USA: Newbury House.

Nation, I. S. P. (2001) Learning vocabulary in another language. Cambridge, UK: Cambridge University Press.

Nijakowska, J. (2008) An experiment with direct multisensory instruction in teaching word reading and spelling to Polish dyslexic learners of English. In Kormos, J. and Kontra, E. (eds) Language learners with special needs. Bristol, UK: Multilingual Matters, 130-157.

Nijakowska, J. (2010) Dyslexia in the foreign language classroom. Bristol, UK: Multilingual Matters.

Oxford, R. L. and Scarcella, R. (1994) Second language vocabulary learning among adults: State of the art in vocabulary instruction. System 22 (2), 231-243.

Peters, E. (2014) The effects of repetition and time of post-test administration on EFL learners' form recall of single words and collocations. Language Teaching Research 18 (1), 75-94.

Pfenninger, S. E. (2015) MSL in the digital age: Effects and effectiveness of computer-mediated intervention for FL dyslexic learners. Studies in Second Language Learning and Teaching 5 (18), 109-133.

Piquer Piriz, A. M. (2008) Reasoning figuratively in early EFL: Some implications for development 
of vocabulary pp. 219- In Boers, F. and Lindstromberg, S. (eds) Cognitive Linguistic Approaches to Teaching Vocabulary and Phraseology. Berlin: Mouton de Gruyter, 219-240.

Sarkadi, Á. (2008) Vocabulary learning in dyslexia: The case of Hungarian learner. In Kormos, J. and Kontra, E. (eds) Language learners with special needs. Bristol, UK: Multilingual Matters, 110129.

Schneider, E. (1999) Multisensory structured metacognitive instruction. Frankfurt am Main, Germany: Peter Lang.

Schneider, E. and Crombie, M. (2003) Dyslexia and foreign language learning. New York, USA: David Fulton Publishers.

Schneider, E. and Ganschow, L. (2000) Dynamic assessment and instructional strategies for learners who struggle to learn a foreign language. Dyslexia 6 (1), 72-82.

Schmitt, N. (2008) Instructed second language vocabulary learning. Language Teaching Research 12 (3), 329-363.

Sparks, R. L. and Ganschow, L. (1993) The effect of multisensory structured language instruction on native language and foreign language aptitude skills of at-risk high school foreign language learners. A replication and follow-up study. Annals of Dyslexia 43 (1), 194-216.

Sparks, R. L., Artzer, M., Patton, J., Ganschow, L., Miller, K., Hordubay, D. J. and Walsh, G. (1998) Benefits of multisensory structured instruction for at-risk foreign language learners: A comparison study of high school Spanish students. Annals of Dyslexia 48 (1), 239-270.

Sparks, R. L., Ganschow, L., Kenneweg, S. and Miller, K. (1991) Use of an Orton-Gillingham approach to teach a foreign language to dyslexic/learning-disabled students: Explicit teaching of phonology in a second language. Annals of Dyslexia 41 (1), 96-118.

Sparks R. L., Ganschow, L., Pohlman, J., Skinner, S. and Artzer, M. (1992) The effects of multisensory structured language instruction on native language and foreign language aptitude skills of at-risk high school foreign language learners. Annals of Dyslexia 42 (1), 25-53.

Szpotowicz, M. (2009) Factor influencing young learners' vocabulary acquisition. In Nikolov, M. (ed) Early learning of modern foreign languages: Processes and outcomes. Bristol, UK: Multilingual Matters, 195-214.

Vilke, M. (1991) Vasě dijete i jezik - materinski, drugi i strani jezik [Your child and language: Mother tongue, second and foreign language]. Zagreb: Školska Knjiga.

Webb, S. (2007) The effect of repetition on vocabulary knowledge. Applied Linguistics 28 (1), 46-65.

Zimmerman, Ch. B. (2014). Teaching and learning vocabulary for second language learners. In Celce-Murcia, M., Brinton, D. and Snow, M. A. (eds) Teaching English as a Second or Foreign Language. (4th edition). Boston, USA: National Geographic Learning, 288-302. 


\section{VIŠEOSJETILNO STRUKTURIRANO UČENJE U SVJETLU FAKTORA DOBI: RAZVOJ RJEČNIKA U ENGLESKOM KAO STRANOM JEZIKU U HRVATSKIH UČENIKA S DISLEKSIJOM}

Cilj ove longitudinalne studije slučaja koja je trajala dvije godine i sedam mjeseci bio je ispitati utjecaj pristupa višeosjetilnog strukturiranog učenja (VSU) u razvoju rječnika u engleskom kao stranom jeziku (ESJ) u dvojice učenika s disleksijom s hrvatskim kao materinskim jezikom koji se razlikuju po dobi - dijete i odrasla osoba. Rezultati su pokazali da učenici s disleksijom u različitim uzrastima mogu poboljšati svoj rječnik u ESJ-u kada ga uče na višeosjetilni i strukturirani način. No, dob je značajan čimbenik. Rezultati ovog istraživanja potvrđuju prethodne ishode studija koje su istraživale utjecaj MSU-a i doprinose nove spoznaje o utjecaju faktora dobi. Pedagoške implikacije studije naglašavaju važnost uključivanja strukturiranog, eksplicitnog i višeosjetilnog pristupa u redovnu nastavu kako bi se učenicima s disleksijom pomoglo da prevladaju teškoće u učenju stranog jezika.

Ključne riječi: disleksija, višeosjetilno strukturirano učenje, engleski kao strani jezik, razvoj rječnika, faktor dobi 